\title{
Visual pathway abnormalities were found in most multiple sclerosis patients despite history of previous optic neuritis
}

\author{
Anormalidades nas vias visuais foram encontradas na maior parte dos pacientes com \\ esclerose múltipla independentemente da história de neurite óptica \\ Stella Maris Costa Castro ${ }^{1}$, Alfredo Damasceno², Benito Pereira Damasceno², Jose Paulo de Vasconcellos', \\ Fabiano Reis ${ }^{3}$, Josie Naomi lyeyasu', Keila Monteiro de Carvalho'
}

\begin{abstract}
Objective: It was to investigate visual field (VF) abnormalities in a group of multiple sclerosis (MS) patients in the remission phase and the presence of magnetic resonance imaging (MRI) lesions in the optic radiations. Methods: VF was assessed in 60 participants (age range 20-51 years): 35 relapsing-remitting MS patients [20 optic neuritis (+), 15 optic neuritis (-)] and 25 controls. MRI (3-Tesla) was obtained in all patients. Results: Visual parameters were abnormal in MS patients as compared to controls. The majority of VF defects were diffuse. All patients except one had posterior visual pathways lesions. No significant difference in lesion number, length and distribution was noted between patients with and without history of optic neuritis. One patient presented homonymous hemianopsia. Conclusion: Posterior visual pathway abnormalities were found in most MS patients despite history of previous optic neuritis.
\end{abstract}

Key words: magnetic resonance imaging, optic neuritis, visual pathways, multiple sclerosis.

\section{RESUMO}

Objetivo: Foi analisar o campo visual (CV) de um grupo de pacientes com esclerose múltipla (EM) na fase remissiva e a presença de lesões nas imagens de ressonância magnética (MRI) na radiação óptica. Método: O CV foi estudado em 60 participantes (faixa etária de 20-51 anos): 35 pacientes EM remitente-recorrente: [20 neurite óptica (+), 15 neurite óptica (-)] e 25 controles. Foram obtidas MRI (3-Tesla) de todos os pacientes. Resultados: Havia alterações visuais nos pacientes com EM quando comparados aos controles. A maioria apresentava defeitos difusos de CV. Todos os pacientes, à exceção de um, apresentaram lesões nas vias visuais posteriores. Não foi observada diferença significativa quanto a número, extensão e distribuição das lesões entre os pacientes com e sem história de neurite óptica. Um paciente apresentou hemianopsia homônima. Conclusão: Anormalidades nas via visuais posteriores foram encontradas na maior parte dos pacientes com EM independentemente da história de neurite óptica.

Palavras-Chave: imagem por ressonância magnética, neurite óptica, vias visuais, esclerose múltipla.

Multiple sclerosis (MS) is a multifocal and relapsing demyelinating disease of the central nervous system with a variable clinical course and pathological features. Optic neuritis $(\mathrm{ON})$ is the most common isolated event, but any part of the visual pathway could be affected, from the retina to the primary visual cortex. It is estimated that $40 \%$ of MS patients experience ON as their first clinical demyelinating event and up to $80 \%$ during the course of their illness ${ }^{1}$. In post-mortem ${ }^{2}$ and magnetic resonance imaging (MRI) ${ }^{3}$ studies in MS patients, optic radiation (OR) lesions were common findings, however, symptomatic retrochiasmal involvement is seldom found ${ }^{4}$.

Visual field (VF) deficits correlate with MRI in neurological diseases that affect $\mathrm{OR}^{5}$. This pathway conveys axons from the lateral geniculate nucleus to the primary visual cortex and injury in this location may impair vision. Standard achromatic perimetry as the Humphrey VF has been used to identify and localize VF defects in most patients with neuro-ophthalmic diseases $^{6}$. In the Optic Neuritis Treatment Trial Study, $8.9 \%$ of patients showed a binocular retrochiasmal type of field defect

\footnotetext{
${ }^{1}$ Department of Ophthalmo-Otolaryngology, Faculty of Medical Sciences, Universidade Estadual de Campinas (UNICAMP), Campinas SP, Brazil;

${ }^{2}$ Department of Neurology, Faculty of Medical Sciences, UNICAMP, Campinas SP, Brazil;

${ }^{3}$ Department of Radiology, Faculty of Medical Sciences, UNICAMP, Campinas SP, Brazil.

Correspondence: Stella Maris da Costa e Castro; Rua Guerino Fiorin 36; 13270-680 Valinhos SP - Brasil; E-mail: stellamccastro@gmail.com

Support: Coordenação de Aperfeiçoamento de Pessoal de Nivel Superior (CAPES).

Conflict of interest: There is no conflict of interest to declare.

Received 25 July 2012; Received in final form 19 December 2012; Accepted 26 December 2012.
} 
at least once during the first year of follow up, but specific analysis of the visual pathway alteration was not performed ${ }^{7}$.

Our aim was to investigate asymptomatic VF defects in a group of MS patients in the remission phase and assess the presence of MRI lesions of the posterior visual pathways.

\section{METHODS}

\section{Subjects}

We studied 35 patients ( 28 women, 7 men), mean age 28 years (range 20 to 51 years), with clinically definite relapsing-remitting MS diagnosed according to revised McDonald criteria $^{8}$ attending our outpatient clinic of the MS centre, at UNICAMP University Hospital, Brazil, between October 2009 to June 2011. They were classified in two groups according to the presence of previous history of one or more episodes of acute optic neuritis, as determined by self-individual and physician report, and confirmed by medical record review: (I) the MS-ON (+) group, comprised of 20 patients with positive history of unilateral or bilateral $\mathrm{ON}$; and (II) the MS-ON (-) group, including 15 patients with no previous $\mathrm{ON}$ history. At the time the assessments were performed, researchers were blinded to the previous optic neuritis history of MS patients. The last episode of ON was at least six months prior to data collection. The patients had no concomitant ocular diseases or systemic conditions that could affect the visual system other than ON/MS. We also studied 25 healthy subjects (19 women, 6 men; mean age 30 years, range 20 to 50 years) for comparison. Written informed consent was obtained from all patients and volunteers before study entry. Procedures adhered to the tenets of Declaration of Helsinki, and the protocol was approved by the local Ethics Committee.

\section{Clinical assessment}

All patients underwent a comprehensive ophthalmic examination of each eye, including refractions prior to vision testing, slit lamp examination, fundoscopy, intraocular pressure, pupil light reflex and ocular motor examinations. We assessed measurements of monocular visual acuity (at $3 \mathrm{~m}$ ) using an Early Treatment Diabetic Retinopathy Study (ETDRS) chart. Monocular color vision was rated with the first 17 plates of Ishihara pseudoisochromatic (24 plates, 2001 edition). For the visual parameters, right and left eye measurements were averaged for the subsequent statistical analyses. Patients were examined through a standardized neurological procedure, and the level of disability was determined using the Expanded Disability Status Scale (EDSS) ${ }^{9}$. Controls had no history of neurologic or ophthalmic disease apart from refractive error of no more than four diopters of spherical equivalent and one diopter of astigmatic refractive error, with best-corrected and logMAR acuities of 0.0 (equivalent to 20/20) or better.

\section{Perimetry}

Achromatic standard perimetry was performed with the Humphrey Field Analyzer II, model 750, Carl Zeiss Meditec software version A-10 (Humphrey, San Leandro, EUA), using the 24-2 Threshold Test with Swedish interactive threshold algorithm fast strategy, foveal threshold on. Criteria for abnormalities were: VF indices (global mean deviation or pattern standard deviation) that were at the $\mathrm{p}<0.05$ probability level or worse, abnormal Glaucoma Hemifield Test by the instrument's software or pattern of loss consistent with ocular abnormalities. VF was considered unreliable if the falsepositive, false-negative and fixation index exceeded $20 \%$. We measured mean deviation, pattern standard deviation, foveal threshold and pattern of VF loss, and compared them with a reference field derived from control data provided by the manufacturer. Each VF was judged to be either normal or abnormal, with all VF chart information used. Diffuse VF loss was characterized by visual loss distributed throughout the field without focal defect. Localized defects were characterized by visual sensitivity worse in one or more areas of the field, with severity depending on the depth and spatial extent of the abnormality ${ }^{10}$. Binocular VF defects were considered as homonymous when a cluster of three or more serial abnormal points was located along the vertical meridian and there were no additional scattered abnormal points that obscured the hemianopic pattern ${ }^{11}$.

\section{MRI acquisition}

All the patients were scanned by a cranial MRI (3-Tesla Intera; Philips Medical System, Best, the Netherlands) using a contrast-enhanced T1-weighted spin-echo and a dualecho sequence for T2-weighted turbo spin-echo sequence, axial fast fluid-attenuated inversion recovery (FLAIR) and double inversion recovery (DIR). All lesions were identified using standard anatomical landmarks, localized on axial slices and identified into OR with FLAIR and/or DIR axial images. High signal-intensity brain lesions in the OR with a size of $\geq 3 \mathrm{~mm}$ were counted and scored in the following manner: group 1=zero, group $2=$ =ne lesion, and group $3=$ two or more lesions. These lesions were classified according their size and scored 0-2 depending on the visualization in one axial plane (group $0=$ no lesion, group $1=3$ until $10 \mathrm{~mm}$, group $2=$ more than $10 \mathrm{~mm}$ ).

\section{Statistical analyses}

Statistical analyses were performed using SPSS 13.0 for Windows (SPSS, Chicago, IL, USA). Means of the visual acuity, Humphrey VF indices (dB) and Ishihara plates' errors were created from each subject. Non-parametric tests were used for comparisons between two groups (Mann-Whitney $\mathrm{U}$ Test) and three groups (Kruskal-Wallis). A conservative threshold of $\mathrm{p}<0.05$ was considered statistically significant. We performed the Bonferroni procedure for comparisons between three groups. 


\section{RESULTS}

\section{Clinical findings}

All patients were in the remission phase of the disease (median 14 months, range 5 to 144 months from the last relapse), and presented median visual acuity equal $0.0 \log \mathrm{MAR}$ (range 0.1 to -0.15). The median time of the last ON episode was 3 years (range 6 to 166 months). None of the patients had been treated with corticosteroids in the three months before evaluation and all were using immunomodulatory drugs. None had afferent pupillary defect.

\section{Visual assessment}

All controls had normal VF. MS patients had mainly diffuse pattern (52\%), followed by normal (34\%) and localized (14\%) VF (the arcuate defect was the most common type). Only one patient had a pattern of binocular defect, a partial homonymous hemianopsia. As compared to controls, MS$\mathrm{ON}(+)$ patients had worse visual acuity $(\mathrm{p}<0.05)$ and worse color vision $(\mathrm{p}<0.001)$. The MS-ON (-) group had worse color vision compared to controls $(\mathrm{p}<0.01)$. The Humphrey VF indices of mean deviation, pattern standard deviation and foveal threshold were worse in MS subgroups than in controls $(\mathrm{p}<0.01)$ (Table).

\section{Post-chiasmal visual pathways}

All but one patient presented OR and/or primary visual cortex lesions. One patient with left partial homonymous hemianopsia had one lesion in the right primary visual cortex with sparing of the occipital pole (Figure).
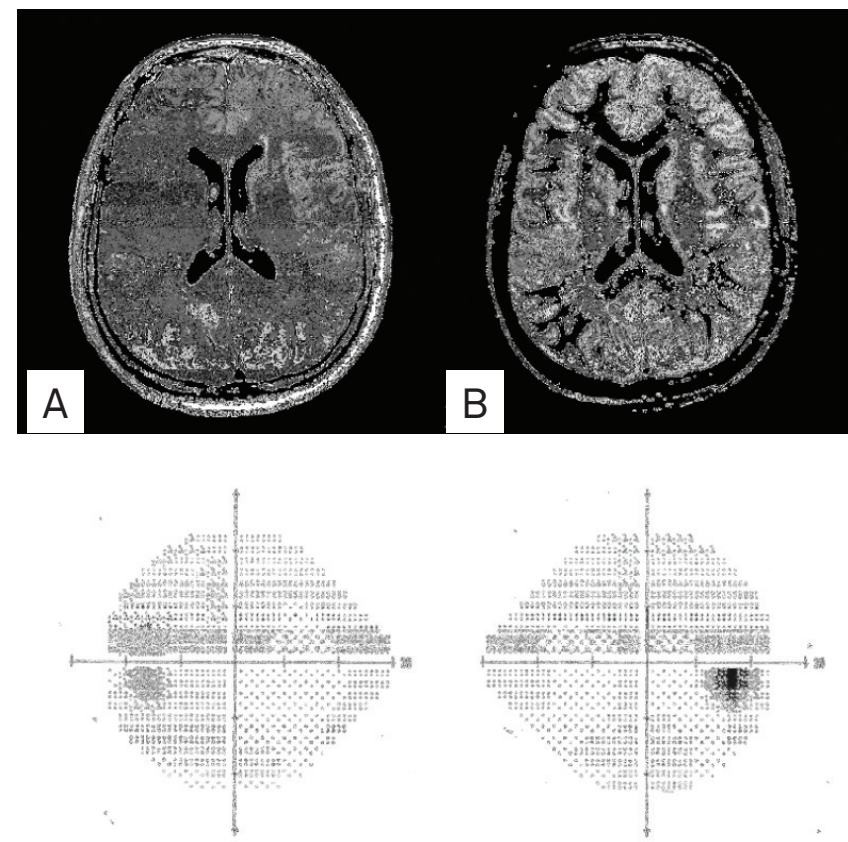

Pattera
Deviation
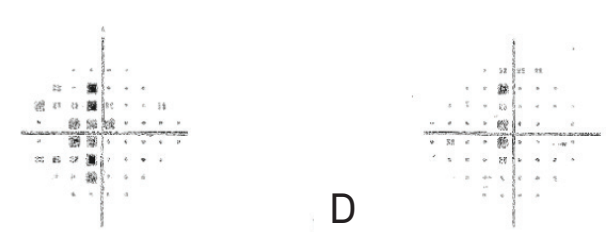

Figure. (A) Axial fluid-attenuated inversion recovery and (B) Axial double inversion recovery magnetic resonance imaging show lesion on right primary visual cortex. 24-2 Swedish interactive threshold algorithm fast Humphrey visual field test shows a partial left homonymous hemianopsia in (C) left eye and (D) right eye.

Table. Demographic and clinical data of multiple sclerosis patients and controls.

\begin{tabular}{|c|c|c|c|}
\hline Summary of clinical data & $\begin{array}{c}\text { MS-ON }(+)-(n=20) \\
\text { mean } \pm S D(\text { range })\end{array}$ & $\begin{array}{c}\text { MS-ON }(-)-(n=15) \\
\text { mean } \pm S D(\text { range })\end{array}$ & $\begin{array}{l}\text { Controls }(n=25) \\
\text { mean } \pm S D(\text { range })\end{array}$ \\
\hline Female sex & 17 & 11 & 19 \\
\hline Age (years) & $30 \pm 8(20-51)$ & $28 \pm 7(20-40)$ & $30 \pm 8(20-50)$ \\
\hline Disease duration (years) & $7.9 \pm 5.5(1.6-23.0)^{a}$ & $4.0 \pm 3.6(<1-12)$ & - \\
\hline EDSS score & $2.0 \pm 1.0(1.0-4.5)$ & $1.8 \pm 0.9(1.0-4.0)$ & - \\
\hline Visual acuity (logMAR) & $-0.00 \pm 0.06(-0.15-0.1)^{b}$ & $-0.03 \pm 0.04(-0.1-0.0)$ & $-0.05 \pm 0.05(-0.1-0.0)$ \\
\hline Humphrey VF - MD (dB) & $-4.02 \pm 3.10(-13.80-0.12)^{b}$ & $-2.53 \pm 1.78(-5.49-0.35)^{b}$ & $-0.60 \pm 0.80(-1.88-1.34)$ \\
\hline Humphrey VF - PSD (dB) & $2.76 \pm 1.87(1.28-8.10)^{b}$ & $2.07 \pm 0.97(1.07-4.87)^{\mathrm{b}}$ & $1.36 \pm 0.21(0.85-1.80)$ \\
\hline Fovea threshold (dB) & $35.30 \pm 1.81(32.0-39.0)^{b}$ & $35.90 \pm 1.65(33.0-38.5)^{b}$ & $37.22 \pm 1.02(35.0-39.5)$ \\
\hline \multirow[t]{2}{*}{ Ishihara error score } & $3.00 \pm 3.8(0.0-16.0)^{\mathrm{b}}$ & $0.73 \pm 0.86(0.0-3.0)^{a, b}$ & $0.22 \pm 0.43(0.0-1.5)$ \\
\hline & $n(\%)$ & n (\%) & $\mathrm{n}(\%)$ \\
\hline Lenght of lesios $3.0-10.0 \mathrm{~mm}$ & $12(60)$ & $9(60)$ & - \\
\hline Multiple lesions & $18(90)$ & $12(80)$ & - \\
\hline Bilateral distribution & $17(85)$ & $12(80)$ & - \\
\hline
\end{tabular}

ap significant value between multiple sclerosis groups; ${ }^{\mathrm{p}} \mathrm{p}$ significant value between multiple sclerosis subgroup and controls with Bonferroni correction. EDSS: Expanded Disability Status Scale; ON (+): optic neuritis history present; ON (-): no optic neuritis history; VF: visual field; MD: mean deviation; PSD: pattern standard deviation; SD: standard deviation; dB: decibel. 
No significant difference in lesion number, length and distribution was noted between the two groups (most prominently of multiple lesions, under $10 \mathrm{~mm}$ and bilateral). Longer lesions and a greater number of lesions in the OR were associated with worse mean deviation and pattern standard deviation on the $\mathrm{VF}$ in the MS-ON (+), but not in the MS-ON (-) group.

\section{DISCUSSION}

Our results confirm that visual pathways are often abnormal during the remission phase of relapsing MS patients even in those without previous history of visual affection.

In this study, abnormal visual fields were found in most patients with MS. The visual function was worse in both MS subgroups compared to controls. These data confirmed previous reports ${ }^{12-14}$, suggesting that chronic axon damage can occur in spite of episodes of acute ON, although stronger correlation was found in eyes with history of ON.

We found frequent abnormalities of the posterior visual pathway on MRI (in 96\% of the patients). This has already been reported in several imaging ${ }^{3,15-17}$ and autopsy studies². OR passes through the periventricular white matter that typically is affected by demyelinating lesions ${ }^{8}$. There are several issues that explain the disparity between radiological and clinical manifestation in the posterior visual pathways: small lesions of the optic radiations and cortex may exist without demonstrable VF defect whereas large lesions are more likely to cause symptomatic field loss ${ }^{4}$. Optical radiation consists of large axons with thick myelin sheaths and low fiber density with wide translucent space $^{18}$, different from the optic nerve fibers which are concentrated in a relatively small volume. This distribution of the fibers, the redundancy and plasticity of the posterior pathway, the possibility of demyelination without detectable axonal conduction deficit and the tendency for inflammation in MS to be centered around venules and not fiber tracts ${ }^{19}$, all these factors may explain the difficulty to correlate neuroimaging and clinical data.
Abnormalities of VF is a characteristic of optic neuritis and the increase of value of mean deviation, a signal of recovery ${ }^{7}$. Although OR lesions often cause binocular defects ${ }^{11}$, we found a homonymous hemianopsia in only one patient. In this case, there was a typical plaque in the contralateral primary visual area on MRI. Similarly, Boldt et al., in a large study of probable MS inpatients ${ }^{20}$, found homonymous hemianopsia in only $2.2 \%$ in the acute phase. Furthermore, in a retrospectively study of homonymous hemianopsia, involving 904 cases, 13 (1.4\%) had multiple sclerosis as the etiologic cause ${ }^{21}$.

There are some papers demonstrating a correlation between retinal and postgeniculate structures. Using diffusion tensor tractography, it was found an association between MRI indices along OR and visual disability at low contrast ${ }^{22}$, and visual disability was found to be related to T2-weighted lesion load in the entire brain, occipital lobe white matter and $\mathrm{OR}^{23}$. In our series, in contrast to these studies, there were no such clinical-radiologic correlations. Longer and greater number of lesions in the OR and worse VF indices were found only in the MS-ON (+) although there is no difference in lesion load between the two MS subgroups. It is more likely that the worsening VF indices mainly reflects the damage to the optic nerves as we can see by optical coherence tomography study ${ }^{12,13,24}$, rather than residual relationship between retinal and OR lesions.

This study has some limitations. Conventional MRI has insufficient sensitivity and specificity to reveal the true extent of pathological changes occurring in MS, as normal appearing white matter may harbor different abnormalities, as seen in non-conventional MRI and pathological works ${ }^{25}$. Another limitation is that we did not assess retinal structural integrity with optical coherence tomography and visual evoked potential because these instruments were not available at our center at the time the study was started.

In conclusion, the present study demonstrates that posterior visual pathway abnormalities are found in most MS patients despite the history of previous ON, but it has failed to demonstrate a link between posterior visual pathways lesions and VF indices.

\section{References}

1. Burton EV, Greenberg BM, Frohman EM. Optic neuritis: a mechanistic view. Pathophysiology 2011;18:81-92.

2. Brownell B, Hughes JT. The distribution of plaques in the cerebrum in multiple sclerosis. J Neurol Neurosurg Psychiatry 1962;25:315-320.

3. Hornabrook RS, Miller DH, Newton MR, et al. Frequent involvement of the optic radiation in patients with acute isolated optic neuritis. Neurology 1992;42:77-79.

4. Plant GT, Kermode AG, Turano G, et al. Symptomatic retrochiasmal lesions in multiple sclerosis: clinical features, visual evoked potentials, and magnetic resonance imaging. Neurology 1992;42:68-76.

5. Visual function 15 years after optic neuritis: a final follow-up report from the Optic Neuritis Treatment Trial. Ophthalmology 2008;115:1079-1082
6. Szatmary G, Biousse V, Newman NJ. Can Swedish interactive thresholding algorithm fast perimetry be used as an alternative to goldmann perimetry in neuro-ophthalmic practice? Arch Ophthalmol 2002;120:1162-1173.

7. Keltner JL, Johnson CA, Spurr JO, Beck RW. Visual field profile of optic neuritis. One-year follow-up in the optic neuritis treatment trial. Arch Ophthalmol 1994;112:946-953.

8. Polman CH, Reingold SC, Edan G, et al. Diagnostic criteria for multiple sclerosis: 2005 revisions to the "McDonald Criteria". Ann Neurol 2005;58:840-846.

9. Kurtzke JF. Rating neurologic impairment in multiple sclerosis: an expanded disability status scale (EDSS). Neurology 1983;33:1444-1452. 
10. Keltner JL, Johnson CA, Spurr JO, Beck RW. Comparison of central and peripheral visual field properties in the optic neuritis treatment trial. Am J Ophthalmol 1999;128:543-553.

11. Zhang X, Kedar S, Lynn MJ, Newman NJ, Biousse V. Homonymous hemianopias: clinical-anatomic correlations in 904 cases. Neurology 2006;66:906-910.

12. Trip SA, Schlottmann PG, Jones SJ, et al. Retinal nerve fiber layer axonal loss and visual dysfunction in optic neuritis. Ann Neurol 2005;58:383-391.

13. Pulicken M, Gordon-Lipkin E, Balcer LJ, et al. Optical coherence tomography and disease subtype in multiple sclerosis. Neurology 2007;69:2085-2092.

14. Trobe JD, Beck RW, Moke PS, Cleary PA. Contrast sensitivity and other vision tests in the optic neuritis treatment trial. Am J Ophthalmol 1996;121:547-553.

15. Ormerod IE, Miller DH, McDonald WI, et al. The role of NMR imaging in the assessment of multiple sclerosis and isolated neurological lesions. A quantitative study. Brain 1987;110:1579-1616.

16. Jacobs L, Kinkel WR, Polachini I, Kinkel RP. Correlations of nuclear magnetic resonance imaging, computerized tomography, and clinical profiles in multiple sclerosis. Neurology 1986;36:27-34.

17. Zivadinov R, Leist TP. Clinical-magnetic resonance imaging correlations in multiple sclerosis. J Neuroimaging 2005;15: S10- S21.
18. Kitajima M, Korogi Y, Takahashi M, Eto K. MR signal intensity of the optic radiation. AJNR Am J Neuroradiol 1996;17:1379-1383.

19. Hawkins K, Behrens MM. Homonymous hemianopia in multiple sclerosis. With report of bilateral case. Br J Ophthalmol 1975;59:334-337.

20. Boldt HA, Haerer AF, Tourtellotte WW, Henderson JW, Dejong RM Retrochiasmal visual field defects from multiple sclerosis. Arch Neurol 1963;8:565-575.

21. Zhang X, Kedar S, Lynn MJ, Newman NJ, Biousse V. Homonymous hemianopia in stroke. J Neuroophthalmol 2006;26:180-183.

22. Reich DS, Smith SA, Gordon-Lipkin EM, et al. Damage to the optic radiation in multiple sclerosis is associated with retinal injury and visual disability. Arch Neurol 2009;66:998-1006.

23. Wu GF, Schwartz ED, Lei T, et al. Relation of vision to global and regional brain MRI in multiple sclerosis. Neurology 2007;69: 2128-2135.

24. Cheng $H$, Laron M, Schiffman JS, Tang RA, Frishman LJ. The relationship between visual field and retinal nerve fiber layer measurements in patients with multiple sclerosis. Invest Ophthalmol Vis Sci 2007;48:5798-5805.

25. Kolappan M, Henderson AP, Jenkins TM, et al. Assessing structure and function of the afferent visual pathway in multiple sclerosis and associated optic neuritis. J Neurol 2009;256:305-319. 